\title{
The Perception and Attitudes of Teachers Towards Class Sizes in Secondary Schools
}

\author{
Eranda Bilali ( Halluni) PhD \\ Department of Education, Faculty of Education, University of Shkodra "Luigj Gurakuqi", Albania \\ Email: erandabilali@yahoo.com
}

\section{Edit Lezha MSc. (PhD on process)}

Faculty of Education, University of Shkodra "Luigj Gurakuqi", Albania

Email: editlezha@gmail.com

\section{Mehdi Kroni PhD}

Faculty of Education, University of Shkodra "Luigj Gurakuqi", Albania

Email:kronimehdi@yahoo.com

\section{Doi:10.5901/ajis.2016.v5n3s1p132}

\begin{abstract}
This study aimed to examine the perception of teachers to teaching large and poorly resourced classes in Albanian secondary schools. Moreover the study further investigated the influence of experience and qualification of teachers' perception on this issue. A qualitative study was conducted on a sample of Albanian teachers to investigate on issues related to functions and disadvantages of smaller classes. Findings indicated that the Albanian teachers perceived class size as important factors to facilitate classroom management, teaching effectiveness, student-teacher interactions, and teachers' workloads. Still, the main concern remains with the fact that a reduction in class size will result in an increase in teaching staff, which could bring teacher quality down. This uncertainty in teacher quality makes the process of identifying or negative impacts on student performance more difficult.
\end{abstract}

Keywords: teacher, perception, class size, quality

\section{Introduction}

Albania's education system faces the challenges of a new philosophy of life, free market economy and European integration, where the achievement of European standards, faces the delicate problems that require solutions. Present and future developments, reforms in pre-university education, have the tendency of internal development, aiming at the integration of the Albanian society in regional and European developments.

One of the most important reforms of the last years is the quality of the teaching process. Since 1993, preuniversity curriculum and teaching-learning process have been and remain subject to continuous improvements. Outdated curriculum frameworks, content not relevant to development trends, methods somewhat archaic and ineffective teaching, remain a challenge in the development of a comprehensive reform and functional quality of education. Student outcomes represent one of the main indicators of the quality and performance of the education system, especially linked with the target to equip students with knowledge and skills to face the challenges and demands of the time by them. International Program for Student Assessment (PISA11), which constitutes one of the most prestigious international studies to measure student achievement is initially implemented in 2001, showed that results were relatively weak. The student / teacher ratio is still far from the levels of the OECD, or 18/1 for preschool education 16/1 to secondary school (According to the preliminary report - Reform of pre-university educational system).

Migration of population from rural to urban areas has increased the capacity in cities and suburban areas schools (up to 50 students per class). In contrast, in some rural areas the ratio student / teacher is very low and poor transport infrastructure does not allow concentration of schools.

At the lower secondary level, class sizes differ significantly among OECD countries and in other G20 countries. Class size continues to be at the forefront of the educational and political agenda for schools, school districts, school boards, education policy makers, parents and other stakeholders. Indeed, class size is a factor that may influence 
parents' choice of a school over another. Smaller class sizes are generally perceived as allowing teachers to spend more time with each student and less time in classroom management, thereby providing better instruction tailored to the students' individual needs, and ensuring higher performance. In this respect, class size may be viewed as an indicator of the quality of a school system. At the lower secondary level and among all OECD countries with comparable data, the average class size varies from 20 students or fewer in Denmark, Estonia, Finland, Iceland, Luxembourg, Slovenia, Switzerland (public institutions) and the United Kingdom, to more than 34 students in Korea. The contrast is even more striking with other G20 countries which provided data (i.e. Argentina, Brazil, China, Indonesia and the Russian Federation); in China, for instance, the number of students per class reaches the 50 students mark (see Indicator D2 in OECD, 2012). It is worth noting that classes tend to be smaller in primary education, the number of students per class growing by two or more students between the primary and the lower secondary level. This trend has intensified between 2000 and 2010, particularly among countries that traditionally reported bigger class sizes, such as Japan and Korea. ( OECD, 2012)

In Albania the structure of the educational system comprises: preschool education; basic education (lower secondary education, special education); upper secondary education (high school, vocational education, socio-cultural education); higher education; adult education. Guideline no. 44 dated 16.10.2014 for some amendments to the guidance of the Ministry of Education and Sport, no. 21, dated 23.07.2010 "On rates of teaching and educational work and the number of students per classroom in pre-university education institutions" under "V" section. Number of students per classroom in pre-university education institutions", point 2 becomes "basic education".

a) Preparatory Class is formed by 25 children.

b) First Class is formed by 26-30 students.

c) Classes II-V are formed by 30-35 students.

Point 3 is: "lower secondary education"

a) Classes are formed by 30-35 students.

Point 4 becomes "upper secondary education"

a) Classes are formed by 30-35 students.

Class size is one of many factors to consider when choosing or estimates a school, but the small size of the class is not the only factor, which ensure a good education. The quality of teaching, school management, school size, parental involvement and other factors are important to take in consideration too.

Since the quality of education depends on the size of the class we will focus our study on the perception of teachers in relation to the functions and disadvantages of classes with large numbers of students.

\section{Methodology}

The methodology used on this study is semi-structured interviews. Interviews were conducted with 35 teachers, of whom 7 math teacher, language and literature teacher 7, 7 teacher of chemistry biology, 7 teachers of foreign languages, 7 teachers of history and geography teaching in lower secondary education in the period from September to November 2016. Meetings with them lasted from 30 to 40 minutes.

All personal interviews are conducted with the consent of the respondent and it was intended for teachers to express themselves on issues that lay down interviews. Questions were built in such a way to give a better idea about the impressions and attitudes of teachers on class size.

\section{Results and Discussions}

Our findings will be divided into two groups: the benefits and disadvantages associated with teachers and benefits and disadvantages related to students.

Teacher-related benefits of smaller classes.

On relation of teachers-related benefits on working in small classes, answers of teachers are listed as follows:

$\checkmark$ There is a greater involvement of students in the classroom.

$\checkmark$ Effective communication between teachers and students.

$\checkmark$ An easy identification of the problems of students.

$\checkmark$ More cooperation between teachers and students.

$\checkmark$ More involvement.

$\checkmark$ Faster rhythm. 
$\checkmark$ Fewer behavioral problems.

$\checkmark$ Teacher is less stressed.

It is important to note that in every interview to mention at least one benefit related with the teaching in small classes. This fact alone shows that the majority of teachers believe that there are real benefits on teaching in classes that are smaller in size. It is interesting to note that some of these benefits are in the interest of the teachers on an individual level, such as dealing with less behavioral problems, less stressed or have less work.

Teachers say that teaching in smaller classes improve student-teacher relationship, strengthens the connection between a teacher and his/her student, making the experience much more enjoyable and meaningful to all participants. Having a small number of students in a given class makes it possible for teachers to become familiar with the students on a personal level. Precisely this feeling of familiarity helps students feel safe and beneficial in their education, which ultimately helps them to perform better in the classroom.

Another benefit of teaching in small classes is that students are more engaged in lessons, activities, projects, work groups, etc.

"From my experience, students pay more attention, try harder and perform better when they are interested in what they are learning" - says 42 - year - old English teacher.

Another teacher with 30 years experience in education, says that teachers should "expect from students to participate in the learning process and take responsibility to reach the goal in the classroom".

Last benefit related with the teacher that I would like to discuss concerns the assessment of student work. As every teacher knows, evaluation of the students takes time, especially when it comes to assess writing assignments. One teacher said "if my role is to teach, I can't be effective when I do not have enough time to do my work. The fact is that providing a positive feedback on working with students is a difficult and stressful job".

Having smaller classes, teachers will feel less stresed, have fewer students to answer and more time to do this. This means that the quality of assessment and student performance will improve, which will result in student performance improvement.

Other benefits revealed on interviews related with teacher are:

$\checkmark$ Better discussions, more meaningful.

$\checkmark$ Better communication, more effective between teachers and students.

$\checkmark$ Quicker identification of students with problems.

$\checkmark$ Contributing more to class discussions.

$\checkmark$ More opportunities for teachers to cope with problems.

$\checkmark$ Instruction specified, personalized, designed to fit the individual needs of students.

$\checkmark$ Quicker pace of instruction.

$\checkmark$ Less behavior problems and classroom management.

$\checkmark$ Teacher is less stressed / less work in class.

Students benefits from smaller classes

$\checkmark$ Students understand better lessons.

$\checkmark$ Teaching is based more on projects.

$\checkmark$ More individual instruction.

$\checkmark$ More collaborative learning.

$\checkmark$ More extension of concentration.

$\checkmark$ More self-confidence.

$\checkmark$ More responsibility.

$\checkmark$ More self-assurance.

$\checkmark$ More effort.

Besides the benefit of teachers in smaller classes even the students can benefit as well. In fact, the benefits related to students are as important as the benefits associated with teachers. Teachers have the idea that small size classes affect students and their performance in different ways.

At almost the majority of interviews teachers claimed that individual instruction is probably the main benefit that students receive in smaller classes. For example, the increase in the amount of time that a teacher has to guide individual his or her students may result in understanding improvement, more effective communication, increased of selfrepresentation, increased effort in class, a larger accountability and a quick improvement in learning. Biology teacher says, "Having the opportunity to deal with each student has made it possible for some students to reach further on their education, compared with those students who do not receive individual attention". 
In addition, having smaller classes can strengthen the sense of community in a class. By creating a learning environment that helps students feel welcome, it is very useful for the performance of students in that class. The reason for creating a community is so important is because it allows students to feel more confidential and open to others, which ultimately makes the learning experience more enjoyable for the participants. Geography teacher, 52, says "A class with a strong sense of community is a very happy environment to participate. Furthermore, students who are happier and like the atmosphere of the class, engage more in the classroom".

Other benefits related with students found out on the interviews are:

$\checkmark$ More opportunities for students to a project based learning.

$\checkmark$ Collaborative learning opportunities.

$\checkmark$ More attention.

$\checkmark$ More safety when working in the laboratory.

$\checkmark$ More choices for students.

Consequences for teacher related with smaller classes are.

$\checkmark$ Lack of competition.

$\checkmark$ Lack of discussion.

$\checkmark$ Less group activities.

$\checkmark$ Lack of diversity of students

In interviews I have included a question that asks participants to list all the consequences associated with teaching in smaller classes. Of course, the main consequence associated with the small size class is likely to be a lack of diversity of students. In this case, the term "diversity" means to refer to the variation of students. This includes learning style of students, perspectives and personalities. The risk of having a lack of diversity of students is that classes can be static flat, and in some cases, boring. The reason for this is that there aren't so many ideas, views, and opinions to be shared / or discussed in class. Eventually, this could lead that discussions in class are not as important or meaningful for the students, this is something that no teacher wants.

History teacher in her interview claimed that, "It happens sometimes in my smaller classes, where we arrive at that point in the discussion where there is nothing left to say". In fact, the small size of the class may impose restrictions on discussions, which can create uneas situation among teachers and students. Another factor contributing to the lack of meaningful discussions has to do with those students who are shy to contribute to discussions. Another teacher described a common scenario, where a student may be hesitant to share his / her thoughts with a group of people, even if the group is small and the members know each other. In cases like these, is "the fear of giving the wrong answers". This can inhibit the valuable discussions. It is therefore understandable that a disadvantage of having smaller classes may be the lack of conversations.

Other consequences found out on interviews that affect teacher are:

$\checkmark$ Lack of competition among students.

$\checkmark$ Few opportunities for large group activities.

$\checkmark$ Groups that are "too connected" may not pay attention to the task.

Consequences for students in smaller classes according to interviews.

$\checkmark$ Lack of competition.

$\checkmark$ Timidity.

$\checkmark$ Diverse personalities.

$\checkmark$ Lack of responsibility.

$\checkmark$ Little variation in classroom.

$\checkmark$ Quick rhythm.

\section{Conclusions}

Participants clearly gave many thoughts and considerations in their responses. Resulting consequences due to the smaller size class listed in the interviews included disadvantages such as lack of diversity of students, meaningful discussion, timidity, lack of competition, etc.

Although these are all valid concerns related to teaching and learning in smaller classes, the study showed that the benefits exceed the disadvantages. Benefits include teachers and students more individualized instructions, more attention to students, improved relations student-teacher engagement and growing interest in classroom learning and meaningful assessment, possibility of analysis. 
Reducing class sizes will help improve the efficiency and quality of teachers. However, teachers with fewer students per classroom are able to guide their instruction more often, which will help to enhance the performance of students. Also, the reduction of class size has the potential to help students to achieve more and to a higher level.

Finally having fewer students, schools encourage their teaching staff to prepare capable students. Considering all, by reducing the size of classes in schools has great potential to improve the quality of teaching and teacher effectiveness and student achievement.

\section{References}

"Average Class Size for Public School Teachers (2002) "National Center for Education Statistics (NCES) Home Page, a Part of the U.S. Department of Education. U.S. Department of Education.

Education at a Glance, 2012-OECD

Hanushek. Eric A.(1998)"Improving Student Achievement: Is Reducing Class Size the Answer? Hoover Institute Stanford University.

Hoxby, Caroline M. (1998) "The Effects of Class Size and Composition on Student Achievement: New Evidence from Natural Popilation Variation. "Working paper no.6869. The National Bureau of Economic Research.

Krueger, Alan B., Eric A. Hanushek, and Jennifer K. Rice.(2002)"The Class Size Debate" Ed. Lawreance Mishel and Richard Rothstein. Economic Policy Institute, 2002.

MAS, Udhëzimi Nr 44, datë 16.10.2014.

Krueger, Alan B."Economic Considerations and Class Size, (2000)."'Working paper no.447.Princeton University

Raporti Paraprak Reforma e sistemit arsimor parauniversitar, Tiranë, Maj 2014.

Pisa 2012 Results-OECD 